\title{
Use of home sphygmomanometers in Turkey: a nation-wide survey
}

\author{
Tekin Akpolat ${ }^{1}$, Yunus Erdem ${ }^{2}$, Ulver Derici ${ }^{3}$, Sehsuvar Erturk ${ }^{4}$, Sali Caglar ${ }^{5}$, Enver Hasanoglu ${ }^{5}$, \\ Oktay Karatan ${ }^{4}$, Sukru Sindel ${ }^{3}$ and Cetin Turgan ${ }^{2}$
}

The purposes of this study were to detect the prevalence of ownership of a home sphygmomanometer among hypertensive subjects through a nation-wide survey, to investigate parameters affecting ownership of a sphygmomanometer, to compare how home blood pressure monitoring (HBPM) was actually used in daily practice with some aspects of the current guidelines, and to discuss what we implemented to increase the reliability of HBPM in a developing country. A total of 2747 hypertensive patients from 34 cities, representative of the Turkish population, were enrolled in the study. A multiple-choice questionnaire was administered to each participant using the computer-assisted telephone interviewing method. Among 2747 hypertensive patients, 1281 of them (46.6\%) had a home sphygmomanometer. Most of the patients were using wrist devices. The factors associated with ownership of a sphygmomanometer were female gender, older age, obesity, higher educational status, higher income level, living in urban areas, awareness of hypertension and anti-hypertensive drug usage. Only $16 \%$ of the devices were used on the advice of a physician. The patients learned usage of their device mainly from the sellers and their relatives. The ownership of a home sphygmomanometer is common among hypertensive patients in Turkey, but regular monitoring of blood pressure before physician visits is rare despite common ownership of these devices. Daily practice of HBPM in Turkey was far from the recommendations of the current guidelines. More effort is needed to improve the reliability of HBPM.

Hypertension Research (2012) 35, 356-361; doi:10.1038/hr.2011.193; published online 17 November 2011

Keywords: automated devices; home blood pressure monitoring; home sphygmomanometer; patient training; wrist devices

\section{INTRODUCTION}

Hypertension is a major public-health problem, leading to myocardial infarction, congestive heart failure, stroke, peripheral vascular disease and chronic kidney disease. Despite many therapeutic options, such as lifestyle modifications and anti-hypertensive agents, failure to achieve target blood pressure (BP) is a frequent problem. ${ }^{1}$ Active involvement of patients in their treatment is a considerable factor in successful management of hypertension. Home BP monitoring (HBPM), a selfmanagement tool that integrates patients into their treatment program, is more common now than it was 10 years ago. Substantial evidence regarding the usefulness of HBPM has accumulated in the last decade. In 2008, two guidelines specifically focusing on the clinical application of HBPM were published by the European Society of Hypertension, ${ }^{2}$ in which its practice version was summarized recently, ${ }^{3}$ and by the American Heart Association, American Society of Hypertension, and Preventive Cardiovascular Nurses Association. ${ }^{4}$ A recent systematic review found HBPM to be superior to office measurements in diagnosing uncontrolled hypertension, assessing anti-hypertensive drug efficiency, and improving patients' compliance and hypertension control. $^{5}$ Moreover, preliminary evidence suggests that HBPM is cost effective. $^{5}$

An accurate and validated ${ }^{6-9}$ sphygmomanometer, correct measurement of BP, and adherence to the current specific guidelines regarding when and how BP should be measured at home settings are essentials of reliable HBPM. However, the prevalence of ownership of a home sphygmomanometer and both awareness and compliance of the patients to the HBPM guidelines are less known, especially in developing and underdeveloped countries. Turkey is a developing country and hypertension prevalence in the adult population has been reported as $31.8 \%$ in Turkey. ${ }^{10}$ The general population of Turkey is 73722988 according to the 2010 census, with individuals aged 18 years or older constituting $69.3 \%$ of the population. Accordingly, the estimated number of hypertensive individuals in Turkey is approximately 16.2 million. The purposes of this study were to detect the prevalence of ownership of a home sphygmomanometer among hypertensive subjects through a nation-wide survey, to investigate parameters affecting ownership of a sphygmomanometer, to compare how HBPM was actually used in daily practice with some aspects of

${ }^{1}$ Ondokuz Mayis University Faculty of Medicine, Samsun, Turkey; ${ }^{2}$ Hacettepe University Faculty of Medicine, Ankara, Turkey; ${ }^{3}$ Gazi University Faculty of Medicine, Ankara, Turkey; ${ }^{4}$ Ankara University Faculty of Medicine, Ankara, Turkey and ${ }^{5}$ Turkish Society of Hypertension and Renal Diseases, Ankara, Turkey

Correspondence: Professor T Akpolat, Ondokuz Mayıs Üniversitesi, Tıp Fakültesi, Nefroloji Bilim Dali, Samsun 55139, Turkey.

E-mail: tekinakpolat@yahoo.com

Received 13 July 2011; revised 7 September 2011; accepted 17 September 2011; published online 17 November 2011 
the current guidelines, and to discuss what we implemented to increase the reliability of HBPM in a developing country.

\section{METHODS}

Study design and participants

Patients with hypertension were recruited from three population-based field studies (Hypertension Incidence in Turkey study, ${ }^{11}$ Salt Intake and Blood Pressure in Turkey study, ${ }^{12}$ and one unpublished study) conducted by the Turkish Society of Hypertension and Renal Diseases. All of the above-mentioned studies used a two-stage stratified sampling method to select a nationally representative sample of the adult population over 18 years of age. Study population was first stratified by province and then by urban/rural areas. Strata were selected by a proportional sampling method according to postal-code lists. Rural areas were defined as towns and villages $80 \mathrm{~km}$ away from city centers. The participants in the three studies were representative of the Turkish population, taking into account the population distribution across urban and rural settings, and male and female sex. Finally, 2747 hypertensive volunteers from 34 cities located in seven geographical provinces, 12 Eurostat regions, of Turkey were enrolled in the study. Hypertensive patients were called by phone, either fixed line or mobile. The basic demographic information for the patients was obtained from the database and was typical of the Turkish population. There were some missing data in the database affecting a few demographic and clinical features of a limited number of participants. Furthermore, a multiplechoice questionnaire (Appendix), including questions regarding the presence of a personal sphygmomanometer and the properties and the use of the sphygmomanometer, was administered to each participant using the computer-assisted telephone interviewing method. If a given patient was not directly available, information was obtained from a relative living at the same household. After obtaining verbal consent, the questionnaires were completed either by interviewing the patients themselves or from their relatives. When it was not possible to get sufficient information from the relatives of the patients, the participants were re-called.

The BP measurements were categorized into five groups; optimal (systolic $\mathrm{BP}<120 \mathrm{~mm} \mathrm{Hg}$ and diastolic $\mathrm{BP}<80 \mathrm{~mm} \mathrm{Hg}$ ), normal-high normal (systolic $\mathrm{BP}=120-139 \mathrm{~mm} \mathrm{Hg}$ or diastolic $\mathrm{BP}=80-89 \mathrm{~mm} \mathrm{Hg}$ ), stage 1 hypertension (systolic $\mathrm{BP}=140-159 \mathrm{~mm} \mathrm{Hg}$ or diastolic $\mathrm{BP}=90-99 \mathrm{~mm} \mathrm{Hg}$ ), stage 2 hypertension (systolic $\mathrm{BP}=160-179 \mathrm{~mm} \mathrm{Hg}$ or diastolic $\mathrm{BP}=100-109 \mathrm{~mm} \mathrm{Hg}$ ) and stage 3 hypertension (systolic $\mathrm{BP} \geqslant 180 \mathrm{~mm} \mathrm{Hg}$ or diastolic $\mathrm{BP} \geqslant 110 \mathrm{~mm} \mathrm{Hg}$ ).

Body mass index (BMI) was calculated by dividing a patient's weight in kilograms by the patient's height in meters squared, and assessed as: $\mathrm{BMI}<18.5$, underweight; BMI of 18.5-24.9, normal; BMI of 25.0-29.9, overweight; $\mathrm{BMI} \geqslant 30$, obese.

\section{Statistical analysis}

Statistical analyses were performed using SPSS 15.0 for Windows software (SPSS Inc., Chicago, IL, USA). Continuous variables were expressed as mean \pm s.d., and categorical variables were expressed as percentages. Comparison between groups was performed using the unpaired Student's- $t$ test, $\chi^{2}$-test, Mantel-Haenszel test, and/or Mann-Whitney $U$ test, as appropriate. Multivariate analysis was performed using multiple logistic regression analysis and included all of the significant covariates, age and BMI in a single step (Enter method). A two-tailed $P$ value of $<0.05$ was considered significant.

\section{RESULTS}

The basic demographic information for the patients is shown in Table 1 . The questionnaires were completed by interviewing the patients themselves $(n=2293,83.5 \%)$ and from their relatives $(n=454,16.6 \%)$. We had missing data from some respondents, but the queries had an overall response rate $>95 \%$, with the exception of two questions: 'Does your device have memory?' and 'The setting of regular BP measurement prior to physician visit'. The response rates were $87 \%$ and $79 \%$ for these two questions, respectively.

Among 2747 hypertensive patients, 1281 of them (46.6\%) had a home sphygmomanometer (95\% CI: 44.7-48.5).
Table 1 Demographic and clinical features of study participants

\begin{tabular}{|c|c|}
\hline Variable & $\mathrm{n}(\%)$ \\
\hline \multicolumn{2}{|l|}{ Gender } \\
\hline Female & $1549(56.4)$ \\
\hline Male & $1198(43.6)$ \\
\hline \multicolumn{2}{|l|}{ Age (years) } \\
\hline 20-29 & $69(2.5)$ \\
\hline 30-39 & $262(9.5)$ \\
\hline $40-49$ & $568(20.7)$ \\
\hline $50-59$ & $736(26.8)$ \\
\hline $60-69$ & $628(22.9)$ \\
\hline$\geqslant 70$ & $484(17.6)$ \\
\hline \multicolumn{2}{|l|}{ Residence } \\
\hline Urban & $1913(69.6)$ \\
\hline Rural & $834(30.4)$ \\
\hline \multicolumn{2}{|l|}{ Educational status } \\
\hline Illiterate & $533(20.0)$ \\
\hline Literate or primary school graduate & $1612(60.6)$ \\
\hline Middle school graduate & $177(6.7)$ \\
\hline High school graduate & $218(8.2)$ \\
\hline University graduate & $120(4.5)$ \\
\hline \multicolumn{2}{|l|}{ Monthly income level } \\
\hline$<500 \mathrm{TL}^{\mathrm{a}}$ & $1650(63.0)$ \\
\hline $500-1500 \mathrm{TL}$ & $848(32.4)$ \\
\hline$\geqslant 1500 \mathrm{TL}$ & $121(4.6)$ \\
\hline \multicolumn{2}{|l|}{ Blood pressure categories } \\
\hline Optimal & $40(1.5)$ \\
\hline Normal-High normal & $225(8.2)$ \\
\hline Stage 1 hypertension & $1519(55.4)$ \\
\hline Stage 2 hypertension & $682(24.9)$ \\
\hline Stage 3 hypertension & $278(10.1)$ \\
\hline \multicolumn{2}{|l|}{ Body mass index } \\
\hline Underweight $\left(<18.5 \mathrm{~kg} \mathrm{~m}^{-2}\right)$ & $45(1.7)$ \\
\hline Normal weight $\left(18.5-24.9 \mathrm{~kg} \mathrm{~m}^{-2}\right)$ & $474(17.4)$ \\
\hline Overweight (25-29.9 $\mathrm{kg} \mathrm{m}^{-2}$ ) & $1081(39.7)$ \\
\hline Obese $\left(\geqslant 30 \mathrm{~kg} \mathrm{~m}^{-2}\right)$ & $1120(41.2)$ \\
\hline Awareness of hypertension & $966(36.1)$ \\
\hline Antihypertensive drug usage & 950 (34.6) \\
\hline
\end{tabular}

a1 Euro=2.3 TL, July 2011.

\section{Device information}

A total of 138 patients had more than one device (134 had two, 4 had three) (Table 2), two patients did not mention the number of devices owned, and the total number of sphygmomanometers was 1421 (Figure 1). Most of the patients were using wrist devices (Figure 1). About $12 \%$ of the sphygmomanometers were acquired within the preceding 12 months, $13 \%$ were acquired from abroad, and $23 \%$ were received as gifts. Overall, $332(26 \%)$ were shared by 347 household hypertensive patients.

\section{Factors associated with ownership of a sphygmomanometer}

Various factors related to ownership of a sphygmomanometer are presented in Table 3. Ownership of a sphygmomanometer was significantly higher among obese participants, older patients, 
Table 2 Types of sphygmomanometers used by patients possessing two or three devices

\begin{tabular}{lc}
\hline & $\begin{array}{c}\text { Number of patients possessing this } \\
\text { type }\end{array}$ \\
\hline Wypes of sphygmomanometers & 100 \\
Wrist+upper arm automated & 21 \\
Non-automated+upper arm automated & 9 \\
Wrist + non-automated+upper arm auto- & 3 \\
mated & \\
Upper arm automated+upper arm automated & 2 \\
Wrist+wrist & 1 \\
Non-automated+type unspecified & 1 \\
Wrist+wrist+non-automated & 1 \\
\hline
\end{tabular}

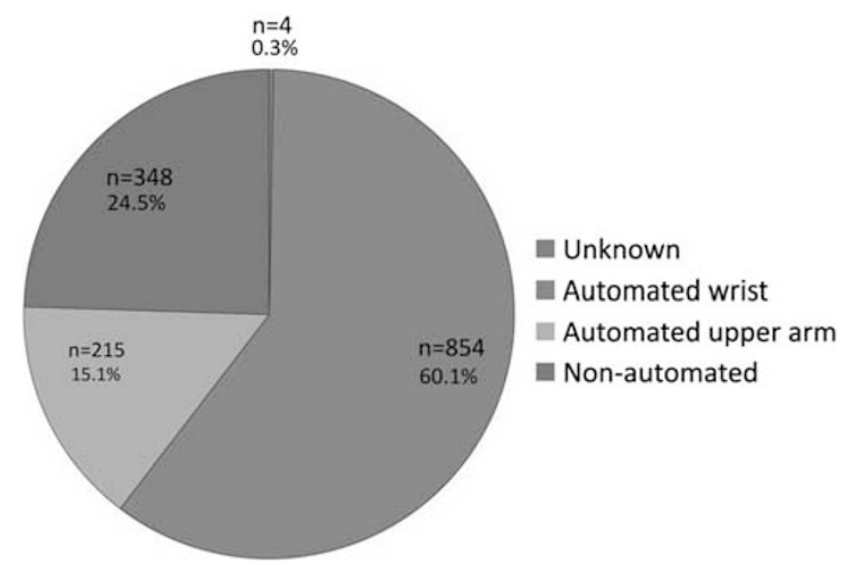

Figure 1 Types of sphygmomanometers owned by the participants A full color version of this figure is available at the Hypertension Research journal online.

participants living in urban areas, participants with higher education status and participants with higher income level.

Multivariate logistic regression analysis demonstrated that the factors associated with ownership of a sphygmomanometer were female gender, older age, obesity, higher educational status, higher income level, living in urban areas, awareness of hypertension during previous study period and anti-hypertensive drug usage (Table 4).

BMI shown in Tables 1, 3 and 4 was calculated from the weight asked in the questionnaire. Using the weight and BMI of the participants present in the database, statistical analyses were performed as well and the statistical significance of the findings did not change (data not shown).

\section{Factors affecting the practice of HBPM}

Only 16\% (175/1067) of the devices were used on the advice of a physician (Figure 2). A total of 138 device owners (10\%) stated that they had not had any training regarding operation of their device. The patients learned usage of their device mainly from the sellers $(50 \%$, $633 / 1278)$ and their relatives $(32 \%, 412 / 1278)$. Nearly $15 \%(61 / 412)$ of the relatives were health-care workers. The contribution of health-care professionals, physician or nurse was $8 \%$, and this figure rose to $13 \%$ with the addition of health-care worker relatives. The manual of the device was the source of instruction for $7 \%$ of the patients.

Overall, 740 sphygmomanometers were reported to include memory, but only 20 patients (3\%) had brought their device when visiting their physician. About 4\% (114/2739) of the patients recorded BP readings before physician visits. The settings in which BP was measured before physician visit were home $(n=87)$ and a health center $(n=3)$.

The frequency of patients who received training from a health-care worker was more common among those having the highest educational status and the highest monthly income. There was no information regarding validation status of the devices and cuff size.

\section{DISCUSSION}

Our survey showed that, in Turkey, $46.6 \%$ of hypertensive patients had a home sphygmomanometer. Neither cost of the sphygmomanometer nor training of these users was reimbursed. Factors affecting the choice of whether or not to purchase a home sphygmomanometer were female gender, older age, obesity, educational status, higher income level, living in urban areas, awareness of hypertension during the preceding study period and anti-hypertensive drug usage. Most of the data regarding ownership of a home sphygmomanometer and HBPM were obtained in studies conducted in developed countries rather than developing and underdeveloped countries, where less use of HBPM may be expected because of lower income. Indeed, the availability of reliable, easily obtainable and affordable devices for BP measurement is a considerable problem in low-resource settings. ${ }^{13}$ Home BP monitoring has been widely used among hypertensive subjects in developed countries for more than 10 years. Even in the 1990's, a telephone survey showed about $70 \%$ prevalence of self-measurement of BP among hypertensive callers in Germany. ${ }^{14}$ Cuspidi et al. ${ }^{15}$ conducted a multicenter survey in Italy and found that 640 (75\%) of 855 hypertensive patients had been regularly performing home BP measurements. Almost all hypertensive patients in the United States and Japan have a home sphygmomanometer ${ }^{4,16,17}$ and $90-95 \%$ of the physicians recommend HBPM in Japan. ${ }^{17}$ Because of lower income level and educational status, the lower rate of ownership of home sphygmomanometers in Turkey, a developing country, compared with developed countries, was not surprising.

Two striking findings of our survey were the lack of training by health-care professionals and the wide-spread use of wrist devices, which were associated with both reliability of HBPM and patient education. Given two other national study findings, ${ }^{10,11}$ which also indicated a close association with patient education, the low control rate of elevated BP and high salt consumption among hypertensive subjects in Turkey, as well as the lack of training of home sphygmomanometer purchasers by health-care professionals, was not surprising. Moreover, the standard of training by the sellers and the patients' relatives was not queried in our survey. The majority of the patients were using wrist devices for HBPM, despite the recommendation of upper-arm devices by three specific guidelines ${ }^{2-4,18}$ and two relevant websites. ${ }^{19,20}$ A national guideline and an official website about HBPM were not available at the time of the current survey. Although the prices of the sphygmomanometers purchased were not queried, the main reason for the selection of a wrist device might be its price, as, in general, the cheapest devices on the market are wrist devices. The validation status for these cheap devices which some cost less than 15 USD were not known. In addition, non-automated auscultatory devices, either aneroid or mercury, which were not recommended for HBPM, accounted for the majority of upper-arm devices. There are many low-priced aneroid sphygmomanometers and stethoscopeaneroid sphygmomanometer sets on the market and their prices are comparable with cheap wrist-automated devices.

Another cardinal feature of a home sphygmomanometer is its validation, ${ }^{6-9}$ which was not queried in our survey because of a 
Table 3 Factors associated with possession of a blood-pressure measuring device in the study population

\begin{tabular}{|c|c|c|c|}
\hline Variable & $\begin{array}{c}\text { Patients possessing a } \\
\text { blood-pressure measuring } \\
\text { device: } n(\%)\end{array}$ & $\begin{array}{l}\text { Statistical test } \\
\text { used for analysis }\end{array}$ & $P$ \\
\hline Gender & & $\chi^{2}$ & \\
\hline Female & $728(47.0)$ & & 0.662 \\
\hline Male & $553(46.2)$ & & \\
\hline Age (years) & & $\begin{array}{l}\text { Mantel-Haenszel } \\
\text { test (linear-by- } \\
\text { linear association) }\end{array}$ & \\
\hline $20-29$ & $23(33.3)$ & & $<0.001$ \\
\hline 30-39 & $72(27.5)$ & & \\
\hline $40-49$ & $224(39.4)$ & & \\
\hline $50-59$ & 382 (51.9) & & \\
\hline $60-69$ & $339(54.0)$ & & \\
\hline$\geqslant 70$ & $241(49.8)$ & & \\
\hline Residence & & $\chi^{2}$ & \\
\hline Urban & $955(49.9)$ & & $<0.001$ \\
\hline Rural & $326(39.1)$ & & \\
\hline Educational Status & & $\begin{array}{l}\text { Mantel-Haenszel } \\
\text { test (linear-by- } \\
\text { linear association) }\end{array}$ & \\
\hline Illiterate & 206 (38.6) & & $<0.001$ \\
\hline $\begin{array}{l}\text { Literate or primary } \\
\text { school graduate } \\
\text { Middle school }\end{array}$ & $742(46.0)$ & & \\
\hline Graduate & $91(51.4)$ & & \\
\hline High school graduate & $132(60.6)$ & & \\
\hline University graduate & 77 (64.2) & & \\
\hline Monthly income level & & $\begin{array}{l}\text { Mantel-Haenszel } \\
\text { test (linear-by- } \\
\text { linear association) }\end{array}$ & \\
\hline$<500 \mathrm{TL}^{\mathrm{a}}$ & $717(43.5)$ & & $<0.001$ \\
\hline 500-1500 TL & $441(52.0)$ & & \\
\hline$\geqslant 1500 \mathrm{TL}$ & $80(66.1)$ & & \\
\hline $\begin{array}{l}\text { Blood pressure } \\
\text { categories }\end{array}$ & & $\begin{array}{l}\text { Mantel-Haenszel } \\
\text { test (linear-by- } \\
\text { linear association) }\end{array}$ & \\
\hline Optimal & $24(60.0)$ & & 0.143 \\
\hline Normal-high normal & $126(56.0)$ & & \\
\hline Stage 1 hypertension & $686(45.2)$ & & \\
\hline Stage 2 hypertension & $307(45.0)$ & & \\
\hline Stage 3 hypertension & $135(48.6)$ & & \\
\hline Body mass index & & $\begin{array}{l}\text { Mantel-Haenszel } \\
\text { test (linear-by- } \\
\text { linear association) }\end{array}$ & \\
\hline $\begin{array}{l}\text { Underweight } \\
\left(<18.5 \mathrm{~kg} \mathrm{~m}^{-2}\right)\end{array}$ & $17(37.8)$ & & $<0.001$ \\
\hline $\begin{array}{l}\text { Normal weight } \\
\left(18.5-24.9 \mathrm{~kg} \mathrm{~m}^{-2}\right)\end{array}$ & $168(35.4)$ & & \\
\hline $\begin{array}{l}\text { Overweight } \\
\left(25-29.9 \mathrm{~kg} \mathrm{~m}^{-2}\right)\end{array}$ & $514(47.5)$ & & \\
\hline Obese $\left(\geqslant 30 \mathrm{~kg} \mathrm{~m}^{-2}\right.$ ) & $569(50.8)$ & & \\
\hline
\end{tabular}

Table 3 (Continued)

\begin{tabular}{|c|c|c|c|}
\hline Variable & $\begin{array}{c}\text { Patients possessing a } \\
\text { blood-pressure measuring } \\
\text { device: } n(\%)\end{array}$ & $\begin{array}{l}\text { Statistical test } \\
\text { used for analysis }\end{array}$ & $\mathrm{P}$ \\
\hline $\begin{array}{l}\text { Awareness of } \\
\text { hypertension }\end{array}$ & & Pearson $\chi^{2}$ & \\
\hline Yes & $565(58.5)$ & & $<0.001$ \\
\hline No & $693(40.6)$ & & \\
\hline $\begin{array}{l}\text { Antihypertensive } \\
\text { drug usage }\end{array}$ & & Pearson $\chi^{2}$ & \\
\hline Yes & $560(58.9)$ & & $<0.001$ \\
\hline No & $720(40.2)$ & & \\
\hline
\end{tabular}

Table 4 Results of multivariate logistic regression analyses for ownership of a blood-pressure measuring device

\begin{tabular}{|c|c|c|c|}
\hline Variables ${ }^{a}$ & Multivariate (p) & Odds ratio & $95 \% \mathrm{Cl}$ \\
\hline Gender (female) & 0.017 & 1.276 & $1.045-1.558$ \\
\hline Age & $<0.001$ & 1.022 & $1.015-1.030$ \\
\hline \multicolumn{4}{|l|}{ Educational status } \\
\hline Illiterate & & 1.0 (referent) & 1.0 (referent) \\
\hline $\begin{array}{l}\text { Literate or primary } \\
\text { school graduate }\end{array}$ & $<0.001$ & 1.939 & $1.543-2.438$ \\
\hline Middle school graduate & $<0.001$ & 3.010 & $2.023-4.478$ \\
\hline High school graduate & $<0.001$ & 4.609 & $3.100-6.851$ \\
\hline University graduate & $<0.001$ & 4.421 & $2.697-7.249$ \\
\hline Living in urban areas & 0.040 & 1.213 & $1.009-1.458$ \\
\hline \multicolumn{4}{|l|}{ Income level } \\
\hline$<500 \mathrm{TL}^{\mathrm{b}}$ & & 1.0 (referent) & 1.0 (referent) \\
\hline 500-1500 TL & 0.122 & 1.176 & $0.958-1.445$ \\
\hline$\geqslant 1500 \mathrm{TL}$ & 0.012 & 1.776 & $1.137-2.773$ \\
\hline Awareness of hypertension & 0.001 & 1.468 & $1.178-1.829$ \\
\hline Antihypertensive drug usage & $<0.001$ & 1.536 & $1.210-1.949$ \\
\hline Body mass index & $<0.001$ & 1.030 & $1.014-1.047$ \\
\hline
\end{tabular}

Abbreviation: $\mathrm{Cl}$, confidence interval.

The variables included in the multivariate logistic regression analysis were: gender, age, educational status, living in urban areas, income level, blood pressure categories, awareness of hypertension, anti-hypertensive drug usage, and body mass index. Only variables having significant differences are shown.

buro=2.3 TL, July 2011.

high possibility of erroneous data collection. Nevertheless, the frequency of validated devices available in Turkey was found to be low, ${ }^{21,22}$ as in England, ${ }^{23}$ indicating a world-wide problem. ${ }^{24}$ As the number of validated wrist devices on the market was limited in Turkey and their price was more expensive than validated upper-arm devices, we believe most of the wrist devices owned by the patients were non-validated.

Incorrect recording of readings and inappropriate cuff size are two factors affecting the reliability of HBPM. ${ }^{4}$ The feature of memory associated with the devices is quite useful and therefore is recommended. ${ }^{2-4}$ Bringing the device to the physician, when visiting, serves to reduce problems due to inaccurate recording of readings and increases the reliability of HBPM, but only a limited number of patients were performing this, according to our survey. As increased prevalence of obesity leads to a larger mean arm circumference in the 


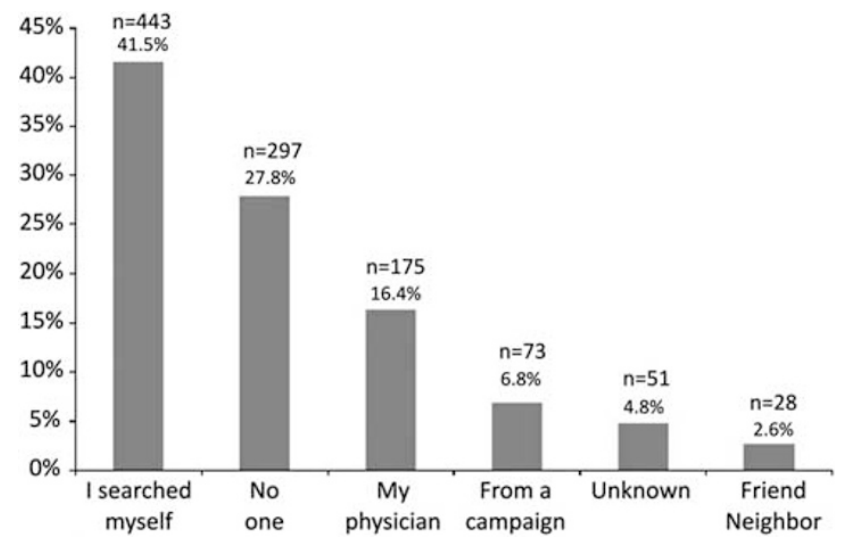

Figure 2 Responses to the query, 'Who recommended the device?' A full color version of this figure is available at the Hypertension Research journal online.

hypertensive population, ${ }^{25}$ and as appropriate cuff size is essential for accurate measurement of $\mathrm{BP}^{2-4}$ overweight and obese patients often require sphygmomanometers with large- or extra-large-sized cuffs. The current study did not investigate the consistency of arm circumference of the user and cuff size of the upper-arm device owned. However, $51 \%$ of the obese patients, a higher percentage than among the non-obese participants, had a sphygmomanometer, and increased BMI was one of the independent factors associated with purchase of a sphygmomanometer.

The major strength of the current study was the representative sample size, which included a great number of participants. However, there were some limitations of the method, computer-assisted telephone interviewing, used in the current study. First, it had the limitations of a telephone survey, which allows only simple questions and despite these simple questions, some data were missing. We could not ask brand, model, price and cuff size of the devices. The relationship between owning a sphygmomanometer and BP control and the performance in monitoring home $\mathrm{BP}$ in patients who received instructions by health-care professionals compared with the rest of the participants were not investigated. In addition, only patients reached by a telephone, mobile or fixed, could be enrolled. In $17 \%$ of the cases, the questionnaire was answered by co-residing relatives instead of the patients themselves, mainly because of fixed-line telephone status. There was not any significant difference between the responses of the patients and their relatives (data not shown). Second, as all participants had been included in a previous field survey, the Hawthorne effect, causing a propensity for purchase of a sphygmomanometer because of sensitized awareness, could not be excluded. Finally, some data (for example, income level, educational status, residential setting and so on.) were obtained during the previous field study period, rather than the current study period. However, we believe that the impact of these limitations on the study findings was small and should not change their final interpretation.

Overall evaluation of the study showed some aspects of current behavioral trends. Despite common ownership of a home sphygmomanometer, daily practice of HBPM in Turkey was far from the recommendations of the current guidelines. ${ }^{2-4,18}$ In spite of common ownership of a home sphygmomanometer, the regular measurement of BP by a small group of patients, before visits with their physicians, indicated ineffective BP measurement at home. We suspect that the main findings of the current study, namely, the lack of training by health-care professionals and the dominance of wrist devices, would also be found in other developing and underdeveloped countries.
Owing to the rarity of validated devices on the market, ${ }^{21-23,26}$ this could be a problem in some developed countries as well. This interpretation was supported by studies published in various countries, such as Canada, England, and Iran. ${ }^{27-29}$ The reimbursement of initial patient education regarding teaching correct HBPM technique could increase the reliability of HBPM and has been recommended by the American Heart Association, American Society of Hypertension and Preventive Cardiovascular Nurses Association. ${ }^{4}$ As an informed public and a trained patient population will be required to increase the reliability of HBPM, a collaborative action plan was formulated by the Turkish Society of Hypertension and Renal Diseases. The hallmarks of this action plan were patient and health-care workers (including physicians), education (mainly using multimedia facilities and the internet), and collaboration with other medical societies aiming to increase public awareness regarding the reliability of HBPM.

\section{CONCLUSION}

The ownership of a home sphygmomanometer is common among hypertensive patients in Turkey, but regular monitoring of BP at home before physician visits is rare despite common ownership of these devices. More efforts, including the participation of national hypertension societies, are needed to improve the reliability of HBPM. Accordingly, an action plan has been launched. The efficacy of this action plan and the need for possible additional measures remain to be seen.

\section{CONFLICT OF INTEREST}

The authors declare no conflict of interest.

\section{ACKNOWLEDGEMENTS}

The study was sponsored by the Turkish Society of Hypertension and Renal Diseases (Ankara, Turkey). The field study, training, and supervision of the field health-care workers, as well as the data collection, were carried out by the OMEGA Contract Research Organization in Turkey. The sponsor, the Turkish Society of Hypertension and Renal Diseases, had assigned the study group and were involved in the study design.

1 Grassi G, Cifkova R, Laurent S, Narkiewicz K, Redon J, Farsang C, Viigimaa M, Erdine S, Brambilla G, Bombelli M, Dell'Oro R, Notari M, Mancia G. Blood pressure control and cardiovascular risk profile in hypertensive patients from central and eastern European countries: results of the BP-CARE study. Eur Heart J 2011; 32: 218-225.

2 Parati G, Stergiou GS, Asmar R, Bilo G, de Leeuw P, Imai Y, Kario K, Lurbe E, Manolis A, Mengden T, O'Brien E, Ohkubo T, Padfield P, Palatini P, Pickering T, Redon J, Revera M, Ruilope LM, Shennan A, Staessen JA, Tisler A, Waeber B, Zanchetti A, Mancia G. European Society of Hypertension guidelines for blood pressure monitoring at home: a summary report of the Second International Consensus Conference on Home Blood Pressure Monitoring. J Hypertens 2008; 26: 1505-1526.

3 Parati G, Stergiou GS, Asmar R, Bilo G, DeLeeuw P, Imai Y, Kario K, Lurbe E, Manolis A, Mengden T, O'Brien E, Ohkubo T, Padfield P, Palatini P, Pickering TG, Redon J, Revera M, Ruilope LM, Shennan A, Staessen JA, Tisler A, Waeber B, Zanchetti A, Mancia G. European Society of Hypertension practice guidelines for home blood pressure monitoring. J Hum Hypertens 2010; 24: 779-785.

4 Pickering TG, Miller NH, Ogedegbe G, Krakoff LR, Artinian NT, Goff D. Call to action on use and reimbursement for home blood pressure monitoring: a joint scientific statement from the American Heart Association, American Society of Hypertension, and Preventive Cardiovascular Nurses Association. J Cardiovasc Nurs 2008; 23: 299-323.

5 Stergiou GS, Bliziotis IA. Home blood pressure monitoring in the diagnosis and treatment of hypertension: a systematic review. Am J Hypertens 2011; 24: 123-134.

6 Association For The Advancement Of Medical Instrumentation. American National Standard for Electronic or Automated Sphygmomanometers: ANSI/AAMI SP10-1993. AAMI: Arlington, VA, 1993.

7 O'Brien E, Petrie J, Littler WA, de Swiet M, Padfield PL, Altman DG, Bland M, Coats A, Atkins N. The British Hypertension Society Protocol for the evaluation of blood pressure measuring devices. J Hypertens 1993; 11: S43-S63.

8 O'Brien E, Pickering T, Asmar R, Myers M, Parati G, Staessen J, Mengden T, Imai Y, Waeber B, Palatini P, Atkins N, Gerin W, Working Group on Blood Pressure Monitoring of the European Society of Hypertension. Working Group on Blood Pressure Monitoring of the European Society of Hypertension International Protocol for validation of blood pressure measuring devices in adults. Blood Press Monit 2002; 7: 3-17. 
9 O’Brien E, Atkins N, Stergiou G, Karpettas N, Parati G, Asmar R, Imai Y, Wang J, Mengden T, Shennan A, Working Group on Blood Pressure Monitoring of the European Society of Hypertension. European Society of Hypertension International Protocol revision 2010 for the validation of blood pressure measuring devices in adults. Blood Press Monit 2010; 15: 23-38.

10 Altun B, Arici M, Nergizoalu G, Derici U, Karatan O, Turgan C, Sindel S, Erbay B, Hasanoğlu E, Cağlar S, for the Turkish Society of Hypertension Renal Diseases. Prevalence, awareness, treatment and control of hypertension in Turkey (the PatenT study) in 2003. J Hypertens 2005; 23: 1817-1823.

11 Erdem Y, Arici M, Altun B, Turgan C, Sindel S, Erbay B, Derici U, Karatan O, Hasanoglu E, Caglar S. The relationship between hypertension and salt intake in Turkish population: SALTURK study. Blood Press 2010; 19: 313-318.

12 Arici M, Turgan C, Altun B, Sindel S, Erbay B, Derici U, Karatan O, Erdem Y, Hasanoglu E, Caglar S. Hypertension incidence in Turkey (HinT): a population-based study. $J$ Hypertens 2010; 28: 240-244.

13 Parati G, Kilama MO, Faini A, Facelli E, Ochen K, Opira C, Mendis S, Wang J, Atkins N, O'Brien E. A new solar-powered blood pressure measuring device for low-resource settings. Hypertension 2010; 56: 1047-1053.

14 Krecke HJ, Lütkes P, Maiwald M. Patient assessment of self-measurement of blood pressure: results of a telephone survey in Germany. J Hypertens 1996; 14: 323-326.

15 Cuspidi C, Meani S, Lonati L, Fusi V, Magnaghi G, Garavelli G, Palumbo G, Pini C, Vaccarella A, Parati G, Leonetti G, Zanchetti A. Prevalence of home blood pressure measurement among selected hypertensive patients: results of a multicenter survey from six hospital outpatient hypertension clinics in Italy. Blood Press 2005; 14: 251-256.

16 Ogihara T, Kikuchi K, Matsuoka H, Fujita T, Higaki J, Horiuchi M, Imai Y, Imaizumi T, Ito S, Iwao H, Kario K, Kawano Y, Kim-Mitsuyama S, Kimura G, Matsubara H, Matsuura $\mathrm{H}$, Naruse M, Saito I, Shimada K, Shimamoto K, Suzuki H, Takishita S, Tanahashi N, Tsuchihashi T, Uchiyama M, Ueda S, Ueshima H, Umemura S, Ishimitsu T, Rakugi H. The Japanese Society of Hypertension Guidelines for the Management of Hypertension (JSH 2009). Hypertens Res 2009; 32: 3-107.

17 Obara T, Ohkubo T, Fukunaga H, Kobayashi M, Satoh M, Metoki H, Asayama K, Inoue R, Kikuya M, Mano N, Miyakawa M, Imai Y. Practice and awareness of physicians

\section{APPENDIX}

The questionnaire administered to the participants

Questions asked to all participants

Whom was called? Patient Relative rooming together

Do you have a sphygmomanometer?

a. Yes b. No

Is your blood pressure (BP) measured regularly and recorded on paper prior to visits to your physician?

$\begin{array}{ll}\text { a. Yes } & \text { b. No }\end{array}$

If the answer is yes, where or how?

a. At home with my device

b. At a pharmacy

c. At a healthcare center

d. Neighbor/Relative

e. Other

\section{Weight:}

Questions asked only to the sphygmomanometer owners

Number of sphygmomanometers at home

Do you take your device along when visiting your physician?

a. Yes b. No

Does your device have memory?

a. Yes b. No

Number of household hypertensive patients

Questions asked for each device

When did you acquire the device?

a. Within the last year

b. More than one year ago regarding home blood pressure measurement in Japan. Hypertens Res 2010; 33: 428-434.

18 Imai Y, Otsuka K, Kawano Y, Shimada K, Hayashi H, Tochikubo O, Miyakawa M, Fukiyama K. Japanese society of hypertension (JSH) guidelines for self-monitoring of blood pressure at home. Hypertens Res 2003; 26: 771-782.

19 dabl ${ }^{\circledR}$ Educational Trust Available from: http://www.dableducational.org Accessed 08 July 2011.

20 BHS-Blood Pressure List Available from: http://www.bhsoc.org/blood_pressure_list.stm. Accessed 8 July 2011.

21 Akpolat T, Dilek M, Aydogdu T, Adibelli Z, Gurgenyatagi Erdem D, Erdem E. Home sphygmomanometers: validation versus accuracy. Blood Press Monit 2009; 14: 26-31.

22 Akpolat T. Obesity, hypertension and home sphygmomanometer cuffs. Eur J Intern Med 2010; 21: 338-340.

23 Coleman A, Steel S, deGreeff A, Shennan A. Validation of the Lloyds pharmacy BP11 oscillometric blood pressure monitor according to the international protocol of the European society of hypertension. Blood Press Monit 2010; 15: 163-166.

24 O'Brien E, Atkins N. State-of-the-market from the dableducational.org website. Blood Press Monit 2007; 12: 377-379.

25 Graves JW, Bailey KR, Sheps SG. The changing distribution of arm circumferences in NHANES III and NHANES 2000 and its impact on the utility of the 'standard adult' blood pressure cuff. Blood Press Monit 2003; 8: 223-227.

26 O'Brien E. State of the market for devices for blood pressure measurement. Blood Press Monit 2001; 6: 281-286.

27 Bancej CM, Campbell N, McKay DW, Nichol M, Walker RL, Kaczorowski J. Home blood pressure monitoring among Canadian adults with hypertension: results from the 2009 Survey on Living with Chronic Diseases in Canada. Can J Cardiol 2010; 26: e152-e157.

28 Tyson MJ, McElduff P. Self-blood-pressure monitoring-a questionnaire study: response, requirement, training, support-group popularity and recommendations. J Hum Hypertens 2003; 17: 51-61.

29 Baghianimoghadam MH, Rahaee Z, Morowatisharifabad MA, Sharifirad G, Andishmand A, Azadbakht L. Effects of education on self-monitoring of blood pressure based on BASNEF model in hypertensive patients. J Res Med Sci 2010; 15: 70-77.
From where did you acquire it?

a. Turkey b. Abroad

How did you acquire it?

a. Purchase b. Gift

If you purchased the device, who recommended it?

a. My physician

b. Friend/Neighbor

c. I searched myself

d. No one

e. From a campaign

f. Other

Type of sphygmomanometer:

a. Non-automated (aneroid, mercury)

b. Automated

1. Upper arm

2. Wrist

Did you get training regarding the use of the device?

a. Yes

b. No

If the answer is yes, from whom or how?

a. My physician

b. My nurse

c. Relative

d. Seller

e. Manual of the device

f. Other 